\title{
New C-H Stretching Vibrational Spectral Features in the Raman Spectra of Gaseous and Liquid Ethanol ${ }^{\dagger}$
}

\author{
Yuanqin Yu, Ke Lin, Xiaoguo Zhou, Hua Wang, Shilin Liu,* and Xingxiao Ma \\ Hefei National Laboratory for Physical Sciences at Microscale, Department of Chemical Physics, University of \\ Science and Technology of China (USTC), Hefei, Anhui 230026, China
}

Received: November 15, 2006; In Final Form: January 15, 2007

\begin{abstract}
Traditionally, the Raman spectrum of ethanol in the $\mathrm{C}-\mathrm{H}$ vibrational stretching region between $2800 \mathrm{~cm}^{-1}$ and $3100 \mathrm{~cm}^{-1}$ had been assigned as three bands of the $-\mathrm{CH}_{2}$ symmetric stretching, the $-\mathrm{CH}_{3}$ symmetric stretching, and the $-\mathrm{CH}_{3}$ antisymmetric stretching. In this report, new Raman spectral features were observed for ethanol and two deuterated ethanols, that is, $\mathrm{CD}_{3} \mathrm{CH}_{2} \mathrm{OH}$ and $\mathrm{CH}_{3} \mathrm{CD}_{2} \mathrm{OH}$, in both gaseous and liquid phases with polarized photoacoustic Raman spectroscopy (PARS) as well as normal Raman spectroscopy. With the aid of depolarization ratio measurements and quantum chemical calculations, different assignments were presented to the complex spectral features in the ethanol Raman spectra. In the gaseous ethanol spectra, the band at $\sim 2882 \mathrm{~cm}^{-1}$ was assigned to the overlapping symmetric stretching vibrational modes of both $-\mathrm{CH}_{2}$ and $-\mathrm{CH}_{3}$; the band at $\sim 2938 \mathrm{~cm}^{-1}$ was assigned to the two symmetric $-\mathrm{CH}_{3}$ Fermi resonance modes and the weak $-\mathrm{CH}_{2}$ antisymmetric stretching mode; and the band at $\sim 2983 \mathrm{~cm}^{-1}$ was assigned to the symmetric $-\mathrm{CH}_{2}$ Fermi resonance mode and the weak $-\mathrm{CH}_{3}$ antisymmetric stretching mode. The liquid ethanol spectral features are similar to the gaseous spectra with a much stronger $-\mathrm{CH}_{3}$ antisymmetric stretching mode and a red shift of about $10 \mathrm{~cm}^{-1}$, which can be attributed to the effects of solvent interactions. The new assignments of both the gaseous and liquid ethanol spectra not only confirmed the recent results from the sum-frequency generation vibrational spectroscopy studies of the ethanol molecules at the air/liquid interface but the differences in the gaseous and liquid phases, as well as at the interfaces, can also provide detailed experimental evidence in understanding of the molecular interactions and dynamics of the ethanol molecule in different chemical environments.
\end{abstract}

\section{Introduction}

In this report, we try to resolve the complex and overlapping features in the $\mathrm{C}-\mathrm{H}$ region of the Raman vibrational spectra of the ethanol molecule in the gaseous and liquid phases. We will show new complex vibrational spectral features and new spectral assignments that have not been clearly examined in the previous literatures.

The vibrational spectrum of a molecule is a fundamental spectroscopic tool in the studies of molecular structure and chemical dynamics. Correct spectral assignment is the first step in the investigation of molecular structure, inter/intramolecular interactions, energy transfer mechanism, chemical reaction dynamics, as well as other transient phenomena. Extensive studies have been conducted on the spectroscopy of simple molecules, such as diatomic, triatomic, and linear molecules, and many of their spectral assignments have been settled. ${ }^{1-4}$ However, combing through the spectral database on the NIST websites $^{2}$ one can find that the vibrational spectra of slightly more complex molecules, especially organic molecules, still remain unavailable or unclear. For complex molecules, Raman and infrared spectra of certain chemical groups, such as $-\mathrm{CH}_{3}$, $-\mathrm{OH}$, and $\mathrm{C}=\mathrm{C}$, are often used as fingerprints to identify chemical species and to study the chemical dynamics for those molecules containing the groups. ${ }^{5}$ Among these spectra, the $\mathrm{C}-\mathrm{H}$ stretching vibrational spectrum in the range of 2800$3100 \mathrm{~cm}^{-1}$ has been widely employed in organic, analytic,

\footnotetext{
† Part of the special issue "Kenneth B. Eisenthal Festschrift".

* Corresponding author. E-mail: slliu@ustc.edu.cn.
}

biological, and polymer chemistry. ${ }^{5-9}$ However, from a spectroscopic point of view, clear understanding and explicit spectral assignment in this region have been quite difficult because of the congestion of various $\mathrm{C}-\mathrm{H}$ vibrational bands, including the symmetric stretching (ss), antisymmetric stretching (as), combination modes, and Fermi resonances.

Among all of the molecules containing the $\mathrm{C}-\mathrm{H}$ groups, ethanol is one of the most important molecules being used as a common fuel or solvent in industry and in daily life, though it is a relatively simple molecule. Ethanol has also usually been taken as a model molecule for theoretical and experimental studies on the vibrational modes of the methyl and methylene groups, on the understanding of the molecular properties in the gas phase, hydrogen-bonding effect and intermolecular vibrational energy redistribution in liquid phase, vapor/liquid interfacial properties, and other chemical dynamical processes. ${ }^{10-14}$ Many IR and Raman spectroscopic studies were performed to investigate the vibrational spectrum of ethanol, especially in the $\mathrm{C}-\mathrm{H}$ stretching region. ${ }^{15-19}$ Thus, one would think that the $\mathrm{C}-\mathrm{H}$ stretching vibration of the ethanol molecule has been thoroughly understood.

It is well known that isotopic substitution is a straightforward way to distinguish the contributions of different $\mathrm{C}-\mathrm{H}$ groups in molecules containing more than one kind of $\mathrm{C}-\mathrm{H}$ group. Perchard et al. ${ }^{15,16}$ measured the IR and Raman spectra of 12 kinds of deuterated ethanol samples and provided assignment to the vibrational spectrum of the liquid ethanol in the $\mathrm{C}-\mathrm{H}$ stretching region. According to Perchard, the bands at around 
$2880 \mathrm{~cm}^{-1}, 2930 \mathrm{~cm}^{-1}$, and $2970 \mathrm{~cm}^{-1}$ were assigned as the symmetric stretching mode of the $-\mathrm{CH}_{2}$ group and the symmetric and antisymmetric stretching modes of $-\mathrm{CH}_{3}$ group, respectively. Kamogawa et al. ${ }^{18}$ also investigated the Raman spectrum of normal ethanol and $\mathrm{CD}_{3} \mathrm{CH}_{2} \mathrm{OH}$ in the liquid phase and provided essentially the same assignment in the $\mathrm{C}-\mathrm{H}$ stretching region.

Such spectral assignments have been widely adopted and applied subsequently to investigate intermolecular interactions and energy transfer mechanisms. ${ }^{10,14,18}$ For example, Dlott et al. ${ }^{10}$ recently used the ultrafast IR pumping and incoherent antiStokes Raman probe technique to study the intramolecular vibrational energy transfer process within the liquid ethanol molecule. The $\mathrm{O}-\mathrm{H}$ stretching vibration at $3300 \mathrm{~cm}^{-1}$ was excited with an infrared laser, and the population changes at the excited $\mathrm{C}-\mathrm{H}$ stretching vibrational states were recorded with the anti-Stokes Raman spectra in the $2800-3100 \mathrm{~cm}^{-1}$ region at different pump-probe delay times. On the basis of Perchard et al.'s spectral assignments, ${ }^{15,16}$ Dlott et al. concluded that the intramolecular vibrational energy transfer process occurs in the ethanol molecule from the $-\mathrm{OH}$ group to the $-\mathrm{CH}_{2}$ group initially and then to the $-\mathrm{CH}_{3}$ groups, via a through-bond energy transfer pathway. Obviously, this conclusion relied heavily on the spectral assignments.

However, it is somehow troublesome that all the Fermi resonance modes were ignored in the assignments from Perchard et al.'s ${ }^{15,16}$ and Kamogawa et al.'s works. ${ }^{18}$ It is known that the Fermi resonance mode generally exists in the $\mathrm{C}-\mathrm{H}$ stretching region of carbon-hydrogen molecules. ${ }^{20-24}$ In the case of ethanol, the first overtones of the bending vibrational modes of both $-\mathrm{CH}_{2}$ and $-\mathrm{CH}_{3}$ groups are located very close to their fundamental symmetric stretching frequencies and may well result in Fermi resonance coupling between them. Thus, the effect of Fermi resonance in the $\mathrm{C}-\mathrm{H}$ stretching region of ethanol should not be ignored. With the Fermi resonance coupling, the intensity of overtone transition is usually comparable to that of the fundamental of the symmetric stretching mode, presenting new spectral features in the $\mathrm{C}-\mathrm{H}$ stretching region. In fact, Atamas et al. ${ }^{23}$ first suggested the existence of Fermi resonance when studying the Raman spectra of a series of liquid alcohols. However, they did not give an unambiguous spectral assignment.

Such Fermi resonance modes were identified very recently when Wang et al. ${ }^{25}$ investigated the sum-frequency generation vibrational spectra (SFG-VS) in the $\mathrm{C}-\mathrm{H}$ stretching region at the air/liquid interfaces of $\mathrm{CH}_{3} \mathrm{CH}_{2} \mathrm{OH}, \mathrm{CD}_{3} \mathrm{CH}_{2} \mathrm{OH}$, and $\mathrm{CH}_{3}$ $\mathrm{CD}_{2} \mathrm{OH}$. They noticed inconsistencies in their results with those of Perchard et al. ${ }^{15,16}$ and Kamogawa et al. ${ }^{18}$ With the aids of isotopic substitution and a set of the polarization selection rules for SFG-VS spectrum based on the symmetry analysis and polarization analysis of the molecular vibrations at interfaces,${ }^{26-28}$ Wang et al. assigned the $2875 \mathrm{~cm}^{-1}$ band to the overlapping symmetric stretching modes of the $-\mathrm{CH}_{2}$ and $-\mathrm{CH}_{3}$ groups, the $2930 \mathrm{~cm}^{-1}$ band to the Fermi resonance of the $-\mathrm{CH}_{3}$ group, and the $2970 \mathrm{~cm}^{-1}$ band to the overlapping antisymmetric stretching of $-\mathrm{CH}_{3}$ and the Fermi resonance of the $-\mathrm{CH}_{2}$ group. ${ }^{25}$ According to such spectral assignments, the $\mathrm{C}-\mathrm{H}$ stretching region of the ethanol, as well as other normal alcohol molecules, is far more complex than previously understood. Consequently, the works based on the assignments by Perchard et al. ${ }^{15,16}$ and Kamogawa et al. ${ }^{18}$ can be questioned and have to be examined. However, even though the SFG-VS spectra of the interfacial ethanol molecule exhibited similar spectral features as in the Raman spectra of the liquid ethanol mol- ecules, ${ }^{25,27,28}$ one can still argue whether the uniquely anisotropic interactions at the molecular interfaces are responsible for the different spectral features and different assignments for the SFGVS spectra in comparison with the gaseous and liquid Raman spectra.

To clarify the ambiguous spectral assignments of the ethanol molecule, certainly more experimental and theoretical works are needed. Measuring and assigning the Raman spectrum of gaseous ethanol is obviously the first step because the Raman spectrum in gas phase is free of intermolecular interaction and can be simpler than that in the liquid phase. Moreover, a highlevel quantum chemical calculation can also be helpful to interpret and assign the vibrational spectrum. Unfortunately, Raman spectrum of gaseous ethanol has been scarcely reported, mainly because of the experimental difficulties in detecting the very weak Raman scattering light in the gas phase compared to the liquid phase.

In this paper, a nonlinear spectroscopic technique, called polarized photoacoustic Raman spectroscopy (PARS), is applied to measure the vibrational spectra of gaseous $\mathrm{CH}_{3} \mathrm{CH}_{2} \mathrm{OH}, \mathrm{CH}_{3}$ $\mathrm{CD}_{2} \mathrm{OH}$, and $\mathrm{CD}_{3} \mathrm{CH}_{2} \mathrm{OH}$. Because in PARS the photoacoustic signal originates from a stimulated Raman scattering process by the two laser beams, the sensitivity and spectral resolution of PARS are much higher than those of conventional spontaneous Raman spectroscopy. In addition, special attention was paid in the PARS experiment to measure the depolarization ratio, $\rho$, which is essential in identification of the symmetry of each spectral feature in the Raman spectrum. Raman spectra of liquid ethanol including isotopic substitutes were also recorded for the comparison with gaseous ethanol. The differences between them can provide more information about the intermolecular interaction in liquid phase, especially the hydrogen-bonding effects. Experiments in gaseous and liquid phases combined with theoretical calculations led to explicit and reliable spectral assignment of the complex and overlapping features in the Raman spectrum of the ethanol molecule in the $\mathrm{C}-\mathrm{H}$ stretching region.

\section{Principle of PARS}

The generation of a stimulated Raman-induced photoacoustic signal in the gaseous phase is quite straightforward. When the frequency difference between two spatially overlapped pump and Stokes laser beams is in resonance with a Raman-active vibrational transition, a stimulated Raman scattering process occurs and the molecules are populated from the ground vibrational level to an excited vibrational level. The molecular population at this excited level will be reduced by subsequent collision-induced vibrational relaxation. Consequently, the translational temperature is increased in the local interaction area, and an excess pressure wave is generated and then detected by a sensitive microphone or a piezoelectric transducer as the photoacoustic signal. The PARS spectrum is obtained by monitoring the photoacoustic signal intensity with the variation of frequency difference between the pump and Stokes laser beams. The sensitivity of the PARS technique is greatly increased in contrast to the direct measurement of spontaneous Raman scatting photons. This method was invented originally by Barret and Berry to measure the Raman spectrum of gaseous methane. ${ }^{29}$ Almost simultaneously, Patel and Tam developed and applied this method to a liquid-phase experiment successfully. ${ }^{30}$ From then on, PARS has been widely applied to gaseous trace component analysis and molecular dynamic processes. ${ }^{31,32}$

The basic theory of PARS was already described elsewhere. ${ }^{31,33}$ Here, only a brief description of PARS is introduced 
and the relation of PARS intensity with laser polarization will be shown. For parallelly polarized pump and Stokes laser beams, the PARS signal intensity, $I$, can be given as

$$
I \propto N L \sigma_{/ /} I_{\mathrm{P}} I_{\mathrm{S}}
$$

where $N$ is the molecular number density, $I_{\mathrm{P}}$ and $I_{\mathrm{S}}$ are the intensities of pump and Stokes laser beams, respectively, $\sigma_{/ /}$is the Raman cross section for parallel polarization of the two laser beams, and $L$ is the effective interaction length between sample and two laser beams. Similarly, when the polarizations of two laser beams are orthogonal to each other, the PARS signal intensity can be written as

$$
I \propto N L \sigma_{\perp} I_{\mathrm{P}} I_{\mathrm{S}}
$$

where $\sigma_{\perp}$ is the Raman cross section for orthogonal polarization of the two laser beams.

In spontaneous Raman processes, the Raman scattering lights can always be decomposed into two orthogonal polarization states: one is perpendicular to the polarization of incident beam whose intensity is denoted as $I_{\perp}$, and the other is parallel to the polarization of incident beam whose intensity is denoted as $I_{/ /}$. The Raman depolarization ratio, $\rho$, is defined as the ratio of $I_{\perp}$ and $I_{/ /}, \rho=I_{\perp} / I_{/ /}$. Because the intrinsic property of stimulated Raman scattering is the same as that of spontaneous Raman scattering, the ratio between cross section $\sigma_{\perp}$ and $\sigma_{/ /}$is also the depolarization ratio, $\rho=\sigma_{\perp} / \sigma_{/ /}$. When the polarizations of two laser beams cross with a certain angle $\theta$, the contributions of parallel and orthogonal polarization configurations give the total PARS signal intensity

$$
\begin{aligned}
& I \propto N L\left(\sigma_{/ /} I_{\mathrm{P}, / /} I_{\mathrm{S}}+\sigma_{\perp} I_{\mathrm{P}, \perp} I_{\mathrm{S}}\right)= \\
& \quad N L\left(\sigma_{/ /} I_{\mathrm{P}} I_{\mathrm{S}} \cos ^{2} \theta+\sigma_{\perp} I_{\mathrm{P}} I_{\mathrm{S}} \sin ^{2} \theta\right)
\end{aligned}
$$

It can also be written in an alternative form

$$
I \propto N L \sigma_{/ /} I_{\mathrm{P}} I_{\mathrm{S}}\left(\cos ^{2} \theta+\rho \sin ^{2} \theta\right)
$$

It is evident that the PARS signal intensity is periodically dependent on the cross angle, $\theta$, between the polarizations of two laser beams. By measuring the $I-\theta$ curve, the depolarization ratio, $\rho$, can be obtained from a global fitting with eq 4 .

Different from the spontaneous Raman experiment, the depolarization ratio obtained with the polarized PARS method is more accurate. First, the depolarization ratio determined from a global fitting of the $I-\theta$ curve will decrease the uncertainty of the ratio between only two intensities $I_{\perp}$ and $I_{/ /}$in the spontaneous Raman experiment, especially for the measurement of small $\rho$, where the scattered intensity $I_{\perp}$ is too weak to be measured accurately. Second, the polarization dependence of the PARS signal is the result of precise matching between polarizations of two laser beams. This is different from the spontaneous Raman experiment, where the Raman scattering light is a spherical wave and is collected in an appreciable solid angle with relatively complex polarizations.

\section{Experiment}

The experimental setup is shown schematically in Figure 1, which is similar to that described previously. ${ }^{34}$ Only a few modifications for the purpose of depolarization ratio measurement were made. The second-harmonic output from a pulsed Nd:YAG laser (Spectra-Physics, Pro-190-10, $532.1 \mathrm{~nm}$, line width $1.0 \mathrm{~cm}^{-1}$, pulse width $10 \mathrm{~ns}$ ) is split into two beams by a quartz plate. About $90 \%$ of the $532.1 \mathrm{~nm}$ laser energy is used

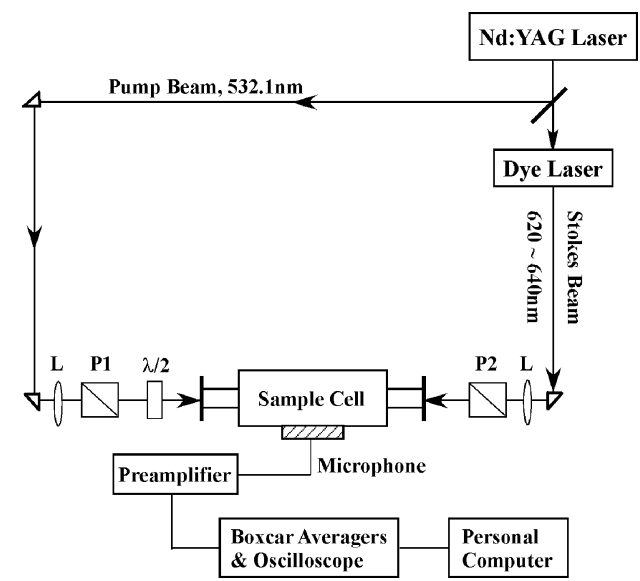

Figure 1. Experimental setup for polarized PARS. L, quartz lens; P1 and P2, Glan-Taylor prism; $\lambda / 2$, half-wave plate.

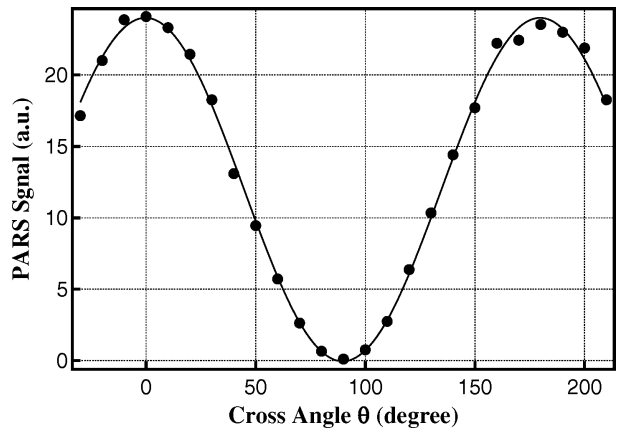

Figure 2. Typical global fitting of the $I-\theta$ curve to determine the depolarization ratio.

to pump a dye laser system (Continuum, ND6000, line width $0.05 \mathrm{~cm}^{-1}$ ) for generating a tunable Stokes laser beam (620$640 \mathrm{~nm}$ ). The residual $10 \%$ of the $532.1 \mathrm{~nm}$ laser is used as a pump beam in PARS experiments. The pump and Stokes laser beams are focused by two lenses with $f=45 \mathrm{~cm}$, and counterpropagate into a homemade photoacoustic cell, where both laser beams are temporally and spatially overlapped with each other. The energies of pump and Stokes beams are typically $10 \mathrm{~mJ} /$ pulse and $3 \mathrm{~mJ} /$ pulse, respectively.

The photoacoustic signal is detected by a microphone, subsequently preamplified, and monitored by an oscilloscope to obtain the PARS signal intensity, $I$, or averaged by a Boxcar integrator and sent to a PC to obtain the PARS spectrum in the gas phase. The spectral intensity is normalized with the power variation of Stokes laser beam. Because the spectral resolution of PARS is determined by the convolution of line widths of two laser beams, the final spectral resolution in present experiment is expected to be $\sim 1.0 \mathrm{~cm}^{-1}$. Pure sample gases were used, and the pressure in the cell was kept at 5.0 Torr.

To measure the depolarization ratio precisely, the pump and Stokes laser beams must be highly polarized, which were achieved by two Glan-Taylor prisms, $\mathrm{P}_{1}$ and $\mathrm{P}_{2}$, in Figure 1 (extinction ratio $<10^{-6}$ ). The polarization of the Stokes beam was fixed in the vertical direction, while that of pump beam was rotated by a $\lambda / 2$ wave plate. In this way, the polarization cross angle, $\theta$, between the two laser beams was controlled. The two focusing lenses were placed ahead of the Glan-Taylor prisms in order to minimize the polarization distortion of the two laser beams by all optics. A typical photoacoustic signal intensity, $I$, versus the polarization cross angle, $\theta$, is shown in Figure 2.

The Raman spectra of liquid ethanol were obtained with a conventional spontaneous Raman experiment instead of the 


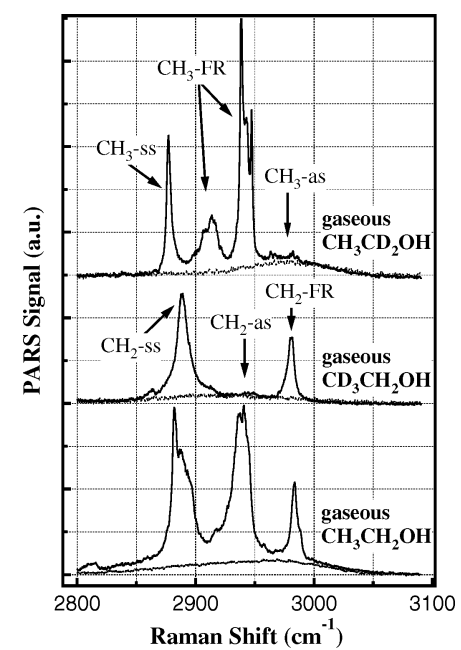

Figure 3. PARS spectra of gaseous $\mathrm{CH}_{3} \mathrm{CD}_{2} \mathrm{OH}, \mathrm{CD}_{3} \mathrm{CH}_{2} \mathrm{OH}$, and $\mathrm{CH}_{3} \mathrm{CH}_{2} \mathrm{OH}$ in the $\mathrm{C}-\mathrm{H}$ stretching region measured under two different laser polarization configurations, parallel (solid lines) and perpendicular (dashed lines). The gas sample pressures were kept at 5.0 Torr, and the energies of pump and Stokes laser beams were $10 \mathrm{~mJ} /$ pulse and 3 $\mathrm{mJ} /$ pulse, respectively. The spectral resolution was $\sim 1 \mathrm{~cm}^{-1}$.

PARS experiment. Similar to the common Raman experiments, we used a CW laser source (Coherent, Verdi-5W, $532 \mathrm{~nm}$ ), a monochromator with a 2400 grooves/mm grating, and a liquidnitrogen-cooled CCD detector (Acton Research, TriplePro) to record the spontaneous Raman spectrum. Liquid samples in a quartz cell (Spectrocell, $10 \times 10 \mathrm{~mm}^{2}$ ) were excited by the laser. The Raman scattering photons were collected at $90^{\circ}$ geometry relative to the incident laser beam with a pair of $f=2.5 \mathrm{~cm}$ and $10 \mathrm{~cm}$ lenses and imaged through a polarization scrambler onto the entrance slit of the monochromator for spectral dispersion. The laser power employed was $0.5 \mathrm{~W}$. The spectral resolution was determined to be $\sim 1.0 \mathrm{~cm}^{-1}$.

Normal ethanol $\left(\mathrm{CH}_{3} \mathrm{CH}_{2} \mathrm{OH}\right)$ was purchased from SigmaAldrich ( $>99.8$, GC grade), and isotope substituted ethanol, $\mathrm{CD}_{3} \mathrm{CH}_{2} \mathrm{OH}(>98 \%)$, and $\mathrm{CH}_{3} \mathrm{CD}_{2} \mathrm{OH}(>98 \%)$ were ordered from Cambridge Isotope Laboratory. These samples were used without further purifications.

\section{Results and Discussion}

4.1. Raman Spectra of Gaseous Ethanol in the $\mathbf{C}-\mathbf{H}$ Stretching Region. The Raman spectra of gaseous $\mathrm{CH}_{3} \mathrm{CH}_{2}-$ $\mathrm{OH}, \mathrm{CD}_{3} \mathrm{CH}_{2} \mathrm{OH}$, and $\mathrm{CH}_{3} \mathrm{CD}_{2} \mathrm{OH}$ in the $\mathrm{C}-\mathrm{H}$ stretching region from 2800 to $3100 \mathrm{~cm}^{-1}$ were recorded with polarized PARS method at both perpendicular $\left(\theta=90^{\circ}\right)$ and parallel $\left(\theta=0^{\circ}\right)$ laser polarization configurations, as presented in Figure 3. Obviously, there is a dramatic change of the PARS intensities for different laser polarization configurations. All of the spectra were measured under the same experimental conditions, such as the temperature, the sample gas pressure in the acoustic cell, and the laser power. In this case, the intensities of different PARS bands of $\mathrm{CH}_{3} \mathrm{CH}_{2} \mathrm{OH}, \mathrm{CD}_{3} \mathrm{CH}_{2} \mathrm{OH}$, and $\mathrm{CH}_{3} \mathrm{CD}_{2} \mathrm{OH}$ can be compared directly to investigate the contributions of different $\mathrm{C}-\mathrm{H}$ groups.

As shown in Figure 3, the Raman spectrum of $\mathrm{CH}_{3} \mathrm{CH}_{2} \mathrm{OH}$ shows three intense bands with peaks located at 2882, 2938, and $2983 \mathrm{~cm}^{-1}$, respectively. The entire spectral contour is basically consistent with previous spectra. By comparing the differences of each vibrational band between normal ethanol and deuterated ethanols, information about the contributions of methyl and/or methylene groups can be obtained. In detail, the left band at $2882 \mathrm{~cm}^{-1}$ in $\mathrm{CH}_{3} \mathrm{CH}_{2} \mathrm{OH}$ including a shoulder at $\sim 2888 \mathrm{~cm}^{-1}$ must contain the contributions of both $-\mathrm{CH}_{3}$ and $-\mathrm{CH}_{2}$ groups because the peaks at $2877 \mathrm{~cm}^{-1}$ in $\mathrm{CH}_{3} \mathrm{CD}_{2} \mathrm{OH}$ and $2888 \mathrm{~cm}^{-1}$ in $\mathrm{CD}_{3} \mathrm{CH}_{2} \mathrm{OH}$ have almost equal intensities. Similarly, the right band at $2983 \mathrm{~cm}^{-1}$ in $\mathrm{CH}_{3} \mathrm{CH}_{2} \mathrm{OH}$ also contains the contributions of both $-\mathrm{CH}_{3}$ and $-\mathrm{CH}_{2}$ groups, although the narrower band at $2981 \mathrm{~cm}^{-1}$ in $\mathrm{CD}_{3} \mathrm{CH}_{2} \mathrm{OH}$ is much stronger than the broad and diffuse band centered at 2978 $\mathrm{cm}^{-1}$ in $\mathrm{CH}_{3} \mathrm{CD}_{2} \mathrm{OH}$. The middle band at $2938 \mathrm{~cm}^{-1}$ in $\mathrm{CH}_{3}-$ $\mathrm{CH}_{2} \mathrm{OH}$ consists of the strong band of the $-\mathrm{CH}_{3}$ group and the weak band of the $-\mathrm{CH}_{2}$ group. The shoulder band at $2917 \mathrm{~cm}^{-1}$ between the left and the middle bands is mainly contributed by the $-\mathrm{CH}_{3}$ group.

In the previous Raman spectroscopic studies of liquid ethanol, ${ }^{16,18}$ the band at $2882 \mathrm{~cm}^{-1}$ in $\mathrm{CH}_{3} \mathrm{CH}_{2} \mathrm{OH}$ was assigned as the symmetric stretching of $-\mathrm{CH}_{2}$ group and the band at $2938 \mathrm{~cm}^{-1}$ was assigned as the symmetric stretching of $-\mathrm{CH}_{3}$ group. Perchard et al. ${ }^{16}$ assigned the band at $2983 \mathrm{~cm}^{-1}$ as the antisymmetric stretching of the $-\mathrm{CH}_{3}$ group, whereas Kamogawa et al. ${ }^{18}$ assigned it as the antisymmetric stretching of $-\mathrm{CH}_{2}$ group. Our sensitive and highly resolved PARS spectra clearly show many differences with previous spectra. Therefore, both of the two previous assignments should be questioned.

As mentioned above, the depolarization ratio, $\rho$, is the symmetry indicator of a Raman-active vibrational mode. The depolarization ratios of each vibrational band in Figure 3 were obtained by measuring the dependence of the PARS signal intensity on the polarization cross angle of pump and Stokes lasers and fitting the measured $I-\theta$ curve with eq 4 . The determined depolarization ratios are summarized in Table 1. The precision of depolarization ratio measurement with this experimental system was checked by the $v_{1}\left(2917 \mathrm{~cm}^{-1}\right)$ and $v_{3}\left(3020 \mathrm{~cm}^{-1}\right)$ vibrational modes of methane. The theoretical value of depolarization ratio, $\rho$, is 0 for the $v_{1}$ mode of $\mathrm{CH}_{4}$ and 0.75 for the $v_{3}$ mode. The uncertainty of $\rho$ values for gaseous ethanol is determinate to be less than 0.005 .

In principle, when using a linearly polarized excitation laser, the $\rho$ value for a symmetric vibrational mode is $0 \leq \rho<0.75$, whereas for an antisymmetric vibrational mode $\rho$ equals $0.75 .^{35}$ Most of the obtained depolarization ratios in Table 1 are very close to zero. The depolarization ratios of only two weak bands, $2945 \mathrm{~cm}^{-1}$ in $\mathrm{CD}_{3} \mathrm{CH}_{2} \mathrm{OH}$ and the broad band centered at 2978 $\mathrm{cm}^{-1}$ in $\mathrm{CH}_{3} \mathrm{CD}_{2} \mathrm{OH}$, are very close to 0.75 . Therefore, these two weak bands are antisymmetric vibrations, and the other bands are attributed to symmetric vibrational modes. With the help of isotopic substitutions and the values of measured depolarization ratios, the spectra in Figure 3 were assigned as labeled in the figure and summarized in Table 1 . Wang et al. ${ }^{25}$ also presented similar spectral assignments to their SFG-VS spectra of air/liquid interfacial methanol in the $\mathrm{C}-\mathrm{H}$ stretching region, except the identification of the weak $-\mathrm{CH}_{2}$ antisymmetric mode and one of the $-\mathrm{CH}_{3}$ Fermi resonance modes. As can be seen from Table 1, our spectral assignments are very different from those in refs 16 and 18 but consistent with the assignments in Wang et al.'s recent study ${ }^{25}$ and also with more spectral features.

The key differences in this study are the accurate determination of the depolarization ratio of the each spectral feature and also the high spectral sensitivity. In fact, Perchard et al. ${ }^{16}$ also measured the depolarization ratios for all of the vibrational bands, but the precision of their measurement was very low. For the bands with $\rho$ close to zero in our experiment, their measured depolarization ratios were around 0.4. In this case it is hard to determine whether the vibrational band is a pure symmetric vibration, or an antisymmetric vibration or a mixture 
TABLE 1: Observed and Calculated Vibrational Frequencies of Gaseous Normal Ethanol and Detuerated Ethanol in the C-H Stretching Region, the Corresponding Depolarization Ratios, and the Spectral Assignments

\begin{tabular}{|c|c|c|c|c|c|c|c|c|}
\hline \multirow[b]{2}{*}{ molecule } & \multicolumn{3}{|c|}{ raman frequency/cm ${ }^{-1}$} & \multirow[b]{2}{*}{ inten $^{d}$} & \multirow[b]{2}{*}{$\rho$} & \multicolumn{3}{|c|}{ raman spectral assignment ${ }^{f}$} \\
\hline & $v_{\mathrm{obs}}$ & $v_{\mathrm{cal}}{ }^{a}$ & $v_{\mathrm{obs}}-v_{\mathrm{cal}}$ & & & this work & ref 16 & ref 18 \\
\hline $\mathrm{CH}_{3} \mathrm{CD}_{2} \mathrm{OH}$ & $\begin{array}{l}2878 \\
2913 \\
2938 \\
2962 \sim 2988\end{array}$ & $\begin{array}{l}2881^{b} \\
2922^{b} \\
2951 \\
3015 \\
3020\end{array}$ & $\begin{array}{r}-3 \\
-9 \\
-13\end{array}$ & $\begin{array}{l}\text { s } \\
\text { w } \\
\text { vs } \\
\text { vw }\end{array}$ & $\begin{array}{l}0.007(2)^{e} \\
0.051(4) \\
0.015(2) \\
\sim 0.75\end{array}$ & $\begin{array}{l}\mathrm{CH}_{3} \text {-ss }{ }^{g} \\
\mathrm{CH}_{3} \text {-FR } \\
\mathrm{CH}_{3} \text {-FR } \\
\mathrm{CH}_{3} \text {-as }\end{array}$ & & \\
\hline $\mathrm{CD}_{3} \mathrm{CH}_{2} \mathrm{OH}$ & $\begin{array}{l}2888 \\
2945 \\
2981\end{array}$ & $\begin{array}{l}2899 \\
2926 \\
2963^{c}\end{array}$ & $\begin{array}{r}-11 \\
19 \\
18\end{array}$ & $\begin{array}{l}\text { vs } \\
\text { vw } \\
\text { s }\end{array}$ & $\begin{array}{l}0.038(2) \\
\sim 0.75 \\
0.045(2)\end{array}$ & $\begin{array}{l}\mathrm{CH}_{2} \text {-ss g } \\
\mathrm{CH}_{2} \text {-as } \\
\mathrm{CH}_{2} \text {-FR }\end{array}$ & & $\begin{array}{l}\mathrm{CH}_{2} \text {-ss } \\
\mathrm{CH}_{2} \text {-as }\end{array}$ \\
\hline $\mathrm{CH}_{3} \mathrm{CH}_{2} \mathrm{OH}$ & $\begin{array}{l}2882 \\
2917\end{array}$ & $\begin{array}{l}2884^{b} \\
2898 \\
2919^{b}\end{array}$ & $\begin{array}{r}-2 \\
-16 \\
-2\end{array}$ & $\begin{array}{l}\text { vs } \\
\text { w }\end{array}$ & $0.051(2)$ & $\begin{array}{l}\mathrm{CH}_{2} \text {-ss \& } \mathrm{CH}_{3} \text {-ss } \\
\mathrm{CH}_{3} \text {-FR }\end{array}$ & $\mathrm{CH}_{2}$-ss & $\mathrm{CH}_{2}$-ss \\
\hline & 2938 & $\begin{array}{l}2924 \\
2956\end{array}$ & $\begin{array}{r}14 \\
-18\end{array}$ & vs & $0.083(2)$ & $\mathrm{CH}_{3}$-FR \& $\mathrm{CH}_{2}$-as & $\mathrm{CH}_{3}$-ss & $\mathrm{CH}_{3}$-Ss \\
\hline & 2983 & $\begin{array}{l}2969^{c} \\
3015 \\
3021\end{array}$ & $\begin{array}{r}14 \\
-32 \\
-38\end{array}$ & $\mathrm{~s}$ & $0.151(2)$ & $\mathrm{CH}_{2}$-FR \& $\mathrm{CH}_{3}$-as & $\mathrm{CH}_{3}$-as & $\mathrm{CH}_{2}$-as \\
\hline
\end{tabular}

${ }^{a}$ Energy scaling factor 0.973 ; Fermi resonances were not referred in calculation. ${ }^{b}$ Expected position of the first overtone of $-\mathrm{CH}_{3}$ bending. ${ }^{c}$ Expected position of the first overtone of $-\mathrm{CH}_{2}$ bending. ${ }^{d}$ vs, very strong; s, strong; w, weak; vw, very weak. ${ }^{e}$ This $\rho$ value may be physically unexplainable. However, this peak is undoubtedly symmetric. ${ }^{f}$ Ss, symmetric stretching; FR, Fermi resonance; as, antisymmetric stretching. ${ }^{g}$ The labeling of the pair of Fermi resonance peaks here is rather arbitrary. We followed the conventional labels for ss and FR.

of both. For example, the depolarization ratio of the $2983 \mathrm{~cm}^{-1}$ band in $\mathrm{CH}_{3} \mathrm{CH}_{2} \mathrm{OH}$ is measured to be 0.15 in our experiment, which would be assigned as a symmetric vibration. But this is not true because this band has contributions from both the antisymmetric vibration of $-\mathrm{CH}_{3}\left(\mathrm{CH}_{3}\right.$-as $)$ and the symmetric Fermi resonance mode of the $-\mathrm{CH}_{2}$ as assigned in Table 1. In contrast, Kamogawa et al. ${ }^{18}$ measured the Raman depolarization ratios of $\mathrm{CH}_{3} \mathrm{CH}_{2} \mathrm{OH}$ but did not measure those of $\mathrm{CD}_{3} \mathrm{CH}_{2-}$ $\mathrm{OH}$, leading to a unreasonable assignment of the $2983 \mathrm{~cm}^{-1}$ band.

It is interesting that the Raman depolarization ratio for the $2882 \mathrm{~cm}^{-1}$ and $2938 \mathrm{~cm}^{-1}$ peaks in the gaseous $\mathrm{CH}_{3} \mathrm{CH}_{2} \mathrm{OH}$ measured in this work are quite close to those of the corresponding peaks in the liquid ethanol as measured by Colles et al. ${ }^{17}$ This clearly indicates that the symmetry properties of these two peaks changed insignificantly going from the gaseous phase to the liquid phase. In contrast, the $\rho$ value for the $2983 \mathrm{~cm}^{-1}$ peaks in the gaseous $\mathrm{CH}_{3} \mathrm{CH}_{2} \mathrm{OH}$ is 0.151 , quite significantly different from the liquid ethanol value of $0.31 .{ }^{17}$ This indicates a significant increase of the asymmetric character of this peak in the liquid phase compared to the gaseous phase, consistent with the much stronger $\mathrm{CH}_{3}$-as peak in the liquid $\mathrm{CH}_{3} \mathrm{CD}_{2} \mathrm{OH}$ spectra (Figure 5) compared to that in the gaseous $\mathrm{CH}_{3} \mathrm{CD}_{2} \mathrm{OH}$ spectra (Figure 3). Because the solvent effects on molecules at the liquid interface are generally in between those in the gaseous and liquid phases, ${ }^{36-38}$ the small changes between the gaseous and liquid Raman spectra also explains why the spectral features in the SFG-VS spectra of the ethanol molecule at the air/liquid interface are essentially the same as those in the gaseous and liquid phases.

4.2. Theoretical Calculations of Raman Spectra of Gaseous Ethanol and Assignments. To ensure the spectral assignments further, density functional theory (DFT) calculations were performed on the Raman spectra in the $\mathrm{C}-\mathrm{H}$ stretching region of gaseous $\mathrm{CH}_{3} \mathrm{CH}_{2} \mathrm{OH}, \mathrm{CH}_{3} \mathrm{CD}_{2} \mathrm{OH}$, and $\mathrm{CD}_{3} \mathrm{CH}_{2} \mathrm{OH}$ using the GAUSSIAN-03 program at the B3LYP/6-311G(d,p) level. ${ }^{39}$ The calculated harmonic vibrational frequencies and the corresponding Raman transition intensities are plotted in Figure 4. The positions of the first overtones of $\mathrm{CH}_{2}$-bending and $\mathrm{CH}_{3}$ bending in the figure are double their calculated fundamental frequencies. During the calculation, various interactions between

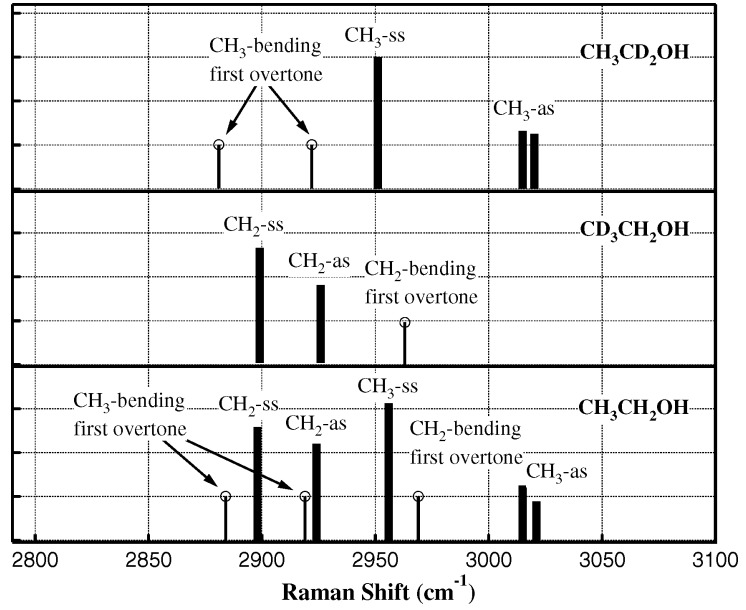

Figure 4. Calculated Raman spectra of gaseous ethanol and deuterated ethanol in the $\mathrm{C}-\mathrm{H}$ regions of $2800-3000 \mathrm{~cm}^{-1}$ at the $\mathrm{B} 3 \mathrm{LYP} / 6-311 \mathrm{G}-$ (d,p) level. The positions of the first overtones of $\mathrm{CH}_{2}$-bending and $\mathrm{CH}_{3}$-bending are just the double of their fundamentals; the Fermiresonance effect was not considered. The overtone intensities are plotted arbitrarily just for presentation.

the vibrational modes were not taken into account. Recently, discussions on the uncertainties in scaling factors for vibrational frequencies indicated that the values of the calculated frequencies can only have two significant figures. ${ }^{40}$ Thus, the uncertainty of the individual frequency in the $2800-3000 \mathrm{~cm}^{-1}$ region can be as big as more than $50 \mathrm{~cm}^{-1}$. Therefore, the theoretical results are shown here just for qualitative comparison with experiment and to interpret the spectra, and the sequence between the calculated overtone frequency of the bending mode and the fundamental stretching mode should not be taken literally.

In the case of the $\mathrm{CD}_{3} \mathrm{CH}_{2} \mathrm{OH}$ molecule, the position of first overtone of the bending vibrational mode $\left(\sim 1480 \mathrm{~cm}^{-1}\right)$ of the $-\mathrm{CH}_{2}$ group is close to the calculated fundamental symmetric stretching frequency of $-\mathrm{CH}_{2}\left(\sim 2900 \mathrm{~cm}^{-1}, \mathrm{CH}_{2}\right.$-ss $)$ with the same symmetry. Fermi resonance would exist between this first overtone and the $\mathrm{CH}_{2}$-ss mode. Because of the Fermi-resonance coupling with the strong fundamental $\mathrm{CH}_{2}$-ss band, the intensity of the first overtone would be enhanced remarkably. In the 


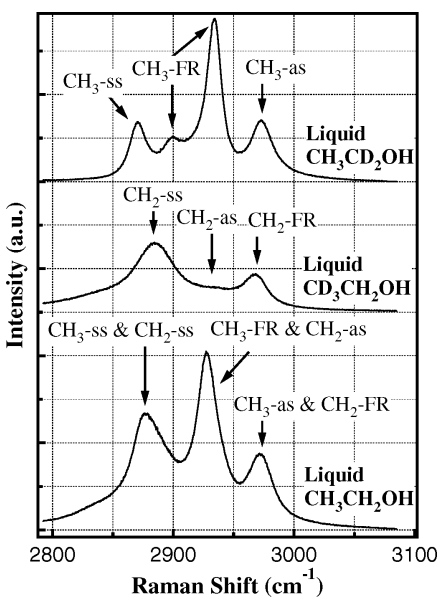

Figure 5. Raman spectra of liquid ethanol and deuterated ethanol. The spectral resolution is $\sim 1 \mathrm{~cm}^{-1}$.

Raman spectrum of $\mathrm{CD}_{3} \mathrm{CH}_{2} \mathrm{OH}$ in Figure 3, there are two peaks at 2888 and $2981 \mathrm{~cm}^{-1}$. Depolarization ratio measurements indicate that they are symmetric vibrational bands. Theoretical calculation shows that the band at $2888 \mathrm{~cm}^{-1}$ is the symmetric stretching of $-\mathrm{CH}_{2}\left(\mathrm{CH}_{2}\right.$-ss $)$ and that at $2981 \mathrm{~cm}^{-1}$ is the symmetric Fermi resonance of $-\mathrm{CH}_{2}\left(\mathrm{CH}_{2}-\mathrm{FR}\right)$. However, as mentioned above, the sequence between the calculated modes should not be taken literally. We therefore assigned the spectrum in Figure 3 following the conventional labels for ss and FR.

In addition, both experiment and theoretical calculation show that the antisymmetric vibrational mode of $-\mathrm{CH}_{2}\left(\mathrm{CH}_{2}\right.$-as) lies between $\mathrm{CH}_{2}$-ss and $\mathrm{CH}_{2}$-FR modes. The theoretically predicted intensity of $\mathrm{CH}_{2}$-as is quite stronger than that experimentally observed. This should be the limitation of DFT calculations when calculating the spectral intensity. Therefore, the very weak but still discernible band at $2945 \mathrm{~cm}^{-1}$ in Figure 3 is confirmed to be the antisymmetric stretching mode of $-\mathrm{CH}_{2}\left(\mathrm{CH}_{2}\right.$-as). The $\mathrm{CH}_{2}$-as band has never been mentioned in previous spectroscopic studies of ethanol. In fact, the $\mathrm{CH}_{2}$-as band had been observed in the Raman spectrum of $\mathrm{CD}_{3} \mathrm{CH}_{2} \mathrm{CD}_{3}$ at $\sim 2925$ $\mathrm{cm}^{-1}{ }^{41}$ Because the $-\mathrm{CH}_{2}$ groups in $\mathrm{CD}_{3} \mathrm{CH}_{2} \mathrm{OH}$ and $\mathrm{CD}_{3}$ $\mathrm{CH}_{2} \mathrm{CD}_{3}$ should have similar Raman spectral characteristics, the existence of the $\mathrm{CH}_{2}$-as band in the $\mathrm{CD}_{3} \mathrm{CH}_{2} \mathrm{OH}$ spectrum is a consequent matter.

In the case of the $\mathrm{CH}_{3} \mathrm{CD}_{2} \mathrm{OH}$ molecule, the frequencies of two $-\mathrm{CH}_{3}$ deformation modes are calculated to be $1440 \mathrm{~cm}^{-1}$ and $1460 \mathrm{~cm}^{-1}$, respectively. Their first overtones are close to the calculated fundamental symmetric stretching vibration of $-\mathrm{CH}_{3}\left(\mathrm{CH}_{3}\right.$-ss, $\left.\sim 2951 \mathrm{~cm}^{-1}\right)$. The Fermi resonances are also expected because of their symmetries and close frequencies. As shown in Table 1, the depolarization ratio measurements of the three apparent bands in Figure 3 indicate that they are symmetric vibrational bands. Theoretical calculation shows that the two bands at around $2878 \mathrm{~cm}^{-1}$ and $2913 \mathrm{~cm}^{-1}$ in Figure 3 are the Fermi resonances of $-\mathrm{CH}_{3}\left(\mathrm{CH}_{3}-\mathrm{FR}\right)$, and the band at $2938 \mathrm{~cm}^{-1}$ is the symmetric stretching of $-\mathrm{CH}_{3}\left(\mathrm{CH}_{3}-\mathrm{ss}\right)$. Such a kind of multiple Fermi resonance commonly exists in the Raman spectrum of $\mathrm{CH}_{3} \mathrm{OH}$ and molecules containing methyl groups. ${ }^{11}$ The broad and weak band centered at $2978 \mathrm{~cm}^{-1}$ in Figure 3 is confirmed to be the antisymmetric stretching mode of $-\mathrm{CH}_{3}\left(\mathrm{CH}_{3}\right.$-as) by both experiment and theoretical calculations. Different from the $-\mathrm{CH}_{2}$ group, the $-\mathrm{CH}_{3}$ group has two kinds of generic antisymmetric stretching modes, the in-plane and out-of-plane vibrations. Macphail et al. ${ }^{42}$ have investigated the splitting and degeneracy of these two vibration modes in alkane molecules. The present calculations indicate that there is an obvious energy interval between these two modes, about $5 \mathrm{~cm}^{-1}$. This is a possible reason for the broad structure centered at $2978 \mathrm{~cm}^{-1}$.

The Raman spectrum of gaseous $\mathrm{CH}_{3} \mathrm{CH}_{2} \mathrm{OH}$ in Figure 3 was assigned subsequently, with the aids of spectral assignments of $\mathrm{CD}_{3} \mathrm{CH}_{2} \mathrm{OH}$ and $\mathrm{CH}_{3} \mathrm{CD}_{2} \mathrm{OH}$ and the supports of theoretical calculations. The first band at $\sim 2882 \mathrm{~cm}^{-1}$ contains contributions of two symmetric vibrational modes, $\mathrm{CH}_{3}$-ss and $\mathrm{CH}_{2}$-ss, following the conventional peak labeling. Similarly, the middle intense band at $\sim 2938 \mathrm{~cm}^{-1}$ consists of two $\mathrm{CH}_{3}$-FR modes and a weak $\mathrm{CH}_{2}$-as mode. The third band at $\sim 2983 \mathrm{~cm}^{-1}$ consists of $\mathrm{CH}_{2}-\mathrm{FR}$ and weak $\mathrm{CH}_{3}$-as. All of the spectral assignments are in reasonably good agreement with the measured depolarization ratios and theoretical calculations.

As proven above, isotopic substitution is very helpful in clarification of the contributions of chemical groups to the spectrum of a complex molecule. However, the Raman spectrum of normal ethanol in the $\mathrm{C}-\mathrm{H}$ stretching region is not a simple summation of the spectra of two deuterated ethanol, $\mathrm{CD}_{3} \mathrm{CH}_{2}-$ $\mathrm{OH}$ and $\mathrm{CH}_{3} \mathrm{CD}_{2} \mathrm{OH}$. The spectral intensities, positions, and widths of the unsubstituted groups will change to some extent. This indicates that the vibrations of the $-\mathrm{CH}_{3}$ and $-\mathrm{CH}_{2}$ groups are not entirely isolated, and they interfere with each other in normal ethanol. As can be seen from Figure 3, the band at 2938 $\mathrm{cm}^{-1}\left(\mathrm{CH}_{3}\right.$-FR) in the Raman spectrum of $\mathrm{CH}_{3} \mathrm{CD}_{2} \mathrm{OH}$ apparently has a fine rotational structure. However, the corresponding band in $\mathrm{CH}_{3} \mathrm{CH}_{2} \mathrm{OH}$ is distinctly broadened and does not have a fine structure, although this band consists of almost completely the $\mathrm{CH}_{3}$-FR vibration.

In short summary, quantum chemistry calculation can help identify possible Raman vibrational frequencies and their Fermi resonances in the $\mathrm{C}-\mathrm{H}$ stretching region. However, considering the calculation uncertainties in determination of the vibrational frequencies, only proper experimental spectral measurements with accurate determination of the Raman depolarization ratio values can provide precise information about the assignment of each vibrational peak.

4.3. Raman Spectra of Liquid Ethanol in $\mathbf{C}-\mathbf{H}$ Stretching Region. The Raman spectra of liquid $\mathrm{CH}_{3} \mathrm{CH}_{2} \mathrm{OH}, \mathrm{CD}_{3} \mathrm{CH}_{2}$ $\mathrm{OH}$, and $\mathrm{CH}_{3} \mathrm{CD}_{2} \mathrm{OH}$ in the $\mathrm{C}-\mathrm{H}$ stretching region were obtained with a conventional spontaneous Raman experiment, as shown in Figure 5. The entire spectral contours are very similar to those in the gas phase. For instance, the three bands of liquid $\mathrm{CH}_{3} \mathrm{CH}_{2} \mathrm{OH}$ with peaks at about 2877, 2927, and 2971 $\mathrm{cm}^{-1}$ are consistent with those in the gas phase at around 2882, 2938 , and $2983 \mathrm{~cm}^{-1}$, with red shifts of $5 \mathrm{~cm}^{-1}, 11 \mathrm{~cm}^{-1}$, and $12 \mathrm{~cm}^{-1}$, respectively. However, the relative intensities of vibrational modes are more significantly changed, and all of the band positions are slightly red-shifted and their widths are broadened. Therefore, the spectral assignments of ethanol in the gas phase can be applied directly to the liquid-phase spectrum. The corresponding spectral assignments are labeled in Figure 5.

The changes of relative intensities of vibrational bands can be attributed to the effect of Fermi resonance because the Fermi resonance is generally sensitive to the energy intervals between the coupling vibrational states, and the energy intervals can be affected by environmental factors, such as the hydrogen-bonding effect. ${ }^{20}$ Moreover, the red shift of the band positions and the bandwidth broadening can also be related to the hydrogenbonding interaction in liquid. Many experimental and theoretical works have confirmed the effects of hydrogen-bond interactions on the IR and Raman spectra of molecules in the liquid phase. ${ }^{43}$ 


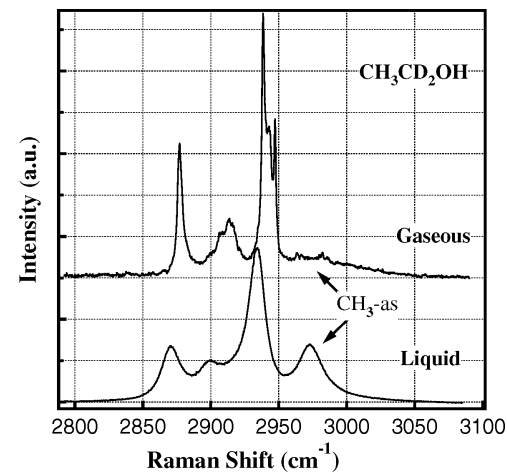

Figure 6. Comparison of Raman spectra between gaseous and liquid $\mathrm{CH}_{3} \mathrm{CD}_{2} \mathrm{OH}$.

However, quantitative explanation of the liquid-phase spectrum is still a significant challenge.

The $\mathrm{CH}_{3}$-as band at $2971 \mathrm{~cm}^{-1}$ in the $\mathrm{CH}_{3} \mathrm{CD}_{2} \mathrm{OH}$ spectrum behaves differently in the gaseous and liquid phase, as compared in Figure 6. In the liquid phase, the band intensity is remarkably enhanced, and the bandwidth is also narrowed. The two weak peaks in the gaseous-phase spectrum seem to overlap with each other to form one band in the liquid phase. There are two possible reasons for the enhancement of the $\mathrm{CH}_{3}$-as band in liquid phase.

First, it is well known that the intermolecular interactions in the condense phase can quench the molecular rotation effectively. Therefore, the rotational contour of a Raman vibrational band can become narrower in the liquid than in the gas phase. Generally, the symmetric vibrational band in the gaseousphase Raman spectrum mainly consists of Q-branch $(\Delta J=0)$ rotational transitions, and thus its spectral contour is sharp and intense, while the antisymmetric band consists of $\Delta J=0, \pm 1$ and \pm 2 rotational transitions, leading to broad and diffuse spectral contour in the gas phase. Alternatively, the rotational quenching in the liquid phase can narrow the width of this $\mathrm{CH}_{3}$ as band effectively, and the band seems to become sharp and intense in liquid phase.

Second, as mentioned above, the $-\mathrm{CH}_{3}$ group in the gaseous $\mathrm{CH}_{3} \mathrm{CD}_{2} \mathrm{OH}$ has two different antisymmetric stretching modes, the in-plane and out-of-plane vibrations, where the plane refers to the plane of $\mathrm{H}-\mathrm{O}-\mathrm{C}-\mathrm{C}-\mathrm{H}$. In fact, these two modes of $-\mathrm{CH}_{3}$ have different energy splitting in different environments. ${ }^{42}$ In the limited case where $-\mathrm{CH}_{3}$ belongs to the $C_{3 v}$ point group, they become degenerated. As indicated in the DFT calculations at the B3LYP/6-311G(d,p) level, in the gaseous $\mathrm{CH}_{3} \mathrm{CD}_{2} \mathrm{OH}$, one of the three $\mathrm{C}-\mathrm{H}$ bond lengths and one of the three $\mathrm{H}-\mathrm{C}-\mathrm{H}$ angles of the $-\mathrm{CH}_{3}$ group are different from the rest, so the $-\mathrm{CH}_{3}$ group in gaseous ethanol can be taken as the $C_{2 v}$ point group. However, in liquid $\mathrm{CH}_{3} \mathrm{CD}_{2} \mathrm{OH}$, the DFT calculations with the CPCM solvent model show that the three $\mathrm{C}-\mathrm{H}$ bond lengths and the three $\mathrm{H}-\mathrm{C}-\mathrm{H}$ angles are almost the same, that is to say, the $-\mathrm{CH}_{3}$ group is close to the $C_{3 v}$ point group. Therefore, in liquid $\mathrm{CH}_{3} \mathrm{CD}_{2} \mathrm{OH}$, the two different antisymmetric stretching modes of $-\mathrm{CH}_{3}$ will become closely degenerated and result in a narrowed and enhanced vibrational band in the Raman spectrum.

In fact, the molecular structure and interactions in the liquid phase are rather complex, and the understanding of spectral differences of molecules in gaseous and liquid phases remains a challenge to both experimental and theoretical researchers. Recently, Guo et al. ${ }^{45}$ used X-ray emission spectroscopy to study the structural properties of liquid methanol. They found that molecules in the pure liquid methanol predominantly persist as hydrogen-bonded chains and rings with six and/or eight molecules of equal abundance. A similar molecular structure may be expected in liquid ethanol formed by hydrogen-bond interactions. The structural difference and the molecular environmental factor cause the enhancement of the $\mathrm{CH}_{3}$-as band in liquid ethanol. Further experiments and theoretical calculations are being performed to explore the nature of spectral differences in gaseous and liquid phases.

\section{Conclusions}

In this report, Raman spectra of $\mathrm{CH}_{3} \mathrm{CH}_{2} \mathrm{OH}$ in the $\mathrm{C}-\mathrm{H}$ stretching region from 2800 to $3100 \mathrm{~cm}^{-1}$ have been measured and reassigned in both the gaseous and liquid phases.

People may generally assume that the assignment of the ethanol vibrational spectra in the literatures has already been clear. However, remarkably different assignments were achieved in this paper for the complex overlapping features in the $\mathrm{C}-\mathrm{H}$ stretching vibrational spectra from accurately measured Raman depolarization ratios in $\mathrm{CH}_{3} \mathrm{CH}_{2} \mathrm{OH}, \mathrm{CH}_{3} \mathrm{CD}_{2} \mathrm{OH}$, and $\mathrm{CD}_{3} \mathrm{CH}_{2-}$ $\mathrm{OH}$ in the gaseous phase. These assignments clearly indicated some mistakes and confusion in the previous Raman spectral assignments. For the gaseous ethanol, the symmetric $\mathrm{CH}_{3}$-ss and $\mathrm{CH}_{2}$-ss bands are overlapped to form the $2882 \mathrm{~cm}^{-1}$ band, the two overlapped symmetric $\mathrm{CH}_{3}$-FR bands and a weak $-\mathrm{CH}_{2}$ antisymmetric band form the $2938 \mathrm{~cm}^{-1}$ band, and the overlapped symmetric $\mathrm{CH}_{2}$-FR and $-\mathrm{CH}_{3}$ antisymmetric bands form the $2983 \mathrm{~cm}^{-1}$ band. For the liquid ethanol, the spectral features are similar to those in the gaseous phase, except for the enhancement of $-\mathrm{CH}_{3}$ antisymmetric band and the red-shifted band positions, which can be attributed to the effects of solvent interactions. The spectral assignments of the gaseous and liquid ethanol are essentially the same. In addition, the detailed differences in the gaseous and liquid phases, as well as at the interfaces, can also provide detailed experimental evidence in understanding the molecular interactions and dynamics of the ethanol molecule in different chemical environments. The new spectral features identified are in agreement with the recent results from the SFG-VS studies of the ethanol and deuterated ethanol at their air/liquid interfaces. ${ }^{25}$ Nevertheless, this study also identified the $\mathrm{CH}_{2}$-as mode, which was not identified in the SFG-VS study because the nearly flat-lying orientational angle of the $-\mathrm{CH}_{2}$ group symmetry axis results in no detectable $\mathrm{CH}_{2}$-as features. ${ }^{44}$ The new assignments of both the gaseous and liquid ethanol spectra not only confirmed the recent results from the SFG-VS studies of the ethanol molecules at the air/ liquid interface but they also clearly indicated that the study employed in this work can provide unique spectral information on the vibrational spectra of complex molecules.

The overlapping spectral features identified in the present spectral assignments can be used to pave reliable groundwork for the understanding of the dynamic processes of the ethanol molecule as well as other complex molecules. It already brought more twist to the understanding of the intramolecular energy transfer mechanism in the liquid alcohol molecules. ${ }^{10}$ The existence of such complex overlapping features in the ethanol molecule directly implies that there are more complexities in the vibrational spectra of longer chain alcohols and other hydrocarbon chain molecules. In this study as well as in the SFG-VS study mentioned above, we identified the stretching spectral features of the $-\mathrm{CH}_{2}$ group and its Fermi resonance when the $-\mathrm{CH}_{2}$ group is directly connected to the $\mathrm{OH}$ group. As discussed by Bain et al., ${ }^{46}$ the $\alpha-\mathrm{CH}_{2}$ group, that is, the $-\mathrm{CH}_{2}$ group directly in connection in between the end $\mathrm{CH}_{3}-$ of the chain and a $-\mathrm{CH}_{2}$ group, exhibits a unique spectral feature 
around the $2860 \mathrm{~cm}^{-1}$. One may immediately ask where the Fermi resonance of this $\alpha-\mathrm{CH}_{2}$ stretching mode shall be. All of these complications in the $\mathrm{C}-\mathrm{H}$ stretching vibrational spectra are both difficult to disentangle and exciting to explore. Nevertheless, the detailed Raman spectral studies of molecules in the gaseous and liquid phases as presented in this report can certainly bring new understanding of molecular vibrational spectroscopy and dynamics interactions in the foreseeable future.

Acknowledgment. We thank Professor Hong-fei Wang for helpful discussions, and Professor Shuiming Hu at USTC for the loan of the Verdi-5W laser. The present work was supported financially by the Natural Science Foundation of China (NSFC, No. 20533070, No. 20573100, No. 20373066).

\section{References and Notes}

(1) Herzberg, G. Molecular Spectra and Molecular Structure; D. Van Nostrand Co. Inc.: New York, 1951.

(2) NIST Chemistry Webbook Database at http://webbook.nist.gov.

(3) Chalmers, J. M.; Griffiths, P. R. Handbook of Vibrational Spectroscopy; John Wiley and Sons Ltd.: New York, 2002.

(4) Jacox, M. E. J. Phys. Chem. Ref. Data 2003, 32, 1.

(5) Silverstein, R. M.; Bassler, G. C.; Morill, T. C. Spectroscopic Identification of Organic Compound; John Wiley, 1974.

(6) Wood, R. W.; Collins, G. Phys. Rev. 1932, 42, 386.

(7) Snyder, R. G.; Aljibury, A. L.; Strauss, H. L.; Casal, H. L.; Gough, K. M.; Murphy, W. F. J. Chem. Phys. 1984, 81, 5352.

(8) Bulhin, B. J.; Krishnan, N. J. Am. Chem. Soc. 1971, 93, 5998

(9) Gruenloh, C. J.; Florio, G. M.; Carney, J. R.; Hagemeister, F. C.;

Zwier, T. S. J. Phys. Chem. A 1999, 103, 496.

(10) Whang, Z. H.; Pakoulev, A.; Dlott, D. D. Science 2002, 296, 2201.

(11) Stanners, C. D.; Du, Q.; Chin, R. P.; Cremer, P.; Somorjai, D. A.;

Shen, Y. R. Chem. Phys. Lett. 1995, 232, 407.

(12) Saiz, L.; Padro, J. A. J. Phys. Chem. B 1997, 101, 78.

(13) Laene, R.; Rauscher, C. Chem. Phys. Lett. 1997, 274, 63.

(14) Sung, J.; Park, K.; Kim, D. J. Phys. Chem. B 2005, 109, 18507.

(15) Perchard, J. P.; Josien, M. L. J. Chim. Phys. 1968, 65, 1834.

(16) Perchard, J. P.; Josien, M. L. J. Chim. Phys. 1968, 65, 1856.

(17) Colles, M. J.; Griffiths, J. E. J. Chem. Phys. 1972, 56, 3384.

(18) Kamogawa, K.; Kaminaka, S.; Kitagawa, T. J. Phys. Chem. 1987, $91,222$.

(19) Bonang, C. C.; Anderson, D. J.; Cameron, S. M.; Kelly, P. B.; Getty, J. D. J. Chem. Phys. 1993, 99, 6245.

(20) Snyder, R. G.; Scherer, J. R. J. Chem. Phys. 1979, 71, 3221

(21) Abbate, S.; Zerbl, G.; Wunder, S. L. J. Phys. Chem. 1982, 86, 3140.

(22) Amrein, A.; Hollenstein, H.; Quack, M.; Zenobi, R; Segall, J.; Zare,

R. N. J. Chem. Phys. 1989, 90, 3944.

(23) Atamas, N. A.; Yaremko, A. M.; Bulavin, L. A.; Pogorelov, V. E.; Berski, S.; Latajka, Z.; Ratajczak, H.; Abkowicz-Bienko, A. J. Mol. Struct. 2002, 605, 187.

(24) Atamas, N. A.; Yaremko, A. M.; Seeger, T.; Leipertz, A.; Bienko, A.; Latajka, Z.; Ratajczak, H.; Barnes, A. J. J. Mol. Struct. 2004, 708, 189.
(25) Gan, W.; Zhang, Z.; Feng, R. R.; Wang, H. F. Chem. Phys. Lett. 2006, 423, 261.

(26) Lu, R.; Gan, W.; Wu, B. H.; Chen, H.; Wang, H. F. J. Phys. Chem. B 2004, 108, 7297.

(27) Lu, R.; Gan, W.; Wu, B. H.; Zhang, Z; Guo, Y.; Wang, H. F. J. Phys. Chem. B 2005, 109, 14118.

(28) Wang, H. F.; Gan, W.; Lu, R.; Rao, Y.; Wu, B. H. Int. Rev. Phys. Chem. 2005, 24, 191.

(29) Barrett, J. J.; Berry, M. J. Appl. Phys. Lett. 1979, 34, 144.

(30) Patel, C. K. N.; Tam, A. C. Appl. Phys. Lett. 1979, 34, 760.

(31) West, G. A.; Barrett, J. J.; Siebert, D. R.; Reddy, K. V. Rev. Sci. Instrum. 1983, 54, 797.

(32) Brown, S. S.; Berghout, H. L.; Crim, F. F. J. Chem. Phys. 1997, 106,5805 2823

(33) West, G. A.; Siebert, D. R.; Barrett, J. J. Appl. Phys. 1980, 51,

(34) Yu, Y. Q.; Wang, H.; Shi, Y.; Li, Q. F.; Dai, J. H.; Liu, S. L.; Ma, X. X. Chin. J. Chem. Phys. 2004, 17, 385.

(35) Long D. A. The Raman Effect: A Unified Treatment of the Theory of Raman Scattering by Molecules; John Wiley \& Sons Ltd.: New York, 2002; Chapter 5.

(36) Wang, H. F.; Borguet, E.; Eisenthal, K. B. J. Phys. Chem. A 1997, 101,713 .

(37) Wang, H. F.; Borguet, E.; Eisenthal, K. B. J. Phys. Chem. B 1998, $102,4927$.

(38) Fu, K. X.; Huang, Y.; Li, X. Y. J. Phys. Chem. B 2006, 110, 10088.

(39) Frisch, M. J.; Trucks, G. W.; Schlegel, H. B.; Scuseria, G. E.; Robb M. A.; Cheeseman, J. R.; Montgomery, J. A., Jr.; Vreven, T.; Kudin, K. N.; Burant, J. C.; Millam, J. M.; Iyengar, S. S.; Tomasi, J.; Barone, V.; Mennucci, B.; Cossi, M.; Scalmani, G.; Rega, N.; Petersson, G. A.; Nakatsuji, H.; Hada, M.; Ehara, M.; Toyota, K.; Fukuda, R.; Hasegawa, J.; Ishida, M.; Nakajima, T.; Honda, Y.; Kitao, O.; Nakai, H.; Klene, M.; Li, X.; Knox, J. E.; Hratchian, H. P.; Cross, J. B.; Bakken, V.; Adamo, C.; Jaramillo, J.; Gomperts, R.; Stratmann, R. E.; Yazyev, O.; Austin, A. J.; Cammi, R.; Pomelli, C.; Ochterski, J. W.; Ayala, P. Y.; Morokuma, K.; Voth, G. A.; Salvador, P.; Dannenberg, J. J.; Zakrzewski, V. G.; Dapprich, S.; Daniels, A. D.; Strain, M. C.; Farkas, O.; Malick, D. K.; Rabuck, A D.; Raghavachari, K.; Foresman, J. B.; Ortiz, J. V.; Cui, Q.; Baboul, A. G.; Clifford, S.; Cioslowski, J.; Stefanov, B. B.; Liu, G.; Liashenko, A.; Piskorz, P.; Komaromi, I.; Martin, R. L.; Fox, D. J.; Keith, T.; Al-Laham, M. A.; Peng, C. Y.; Nanayakkara, A.; Challacombe, M.; Gill, P. M. W. Johnson, B.; Chen, W.; Wong, M. W.; Gonzalez, C.; Pople, J. A. Gaussian 03, revision B.05; Gaussian, Inc.: Wallingford, CT, 2004

(40) Irikura, K. K.; Johnson, R. D., III; Kacker, R. N. J. Phys. Chem. A 2005, 109, 8430 .

(41) Zerbi, G.; Abbate, S. Chem. Phys. Lett. 1981, 80, 455.

(42) Macphail, R. A.; Synder, R. G.; Strauss, H. L. J. Chem. Phys. 1982, 77,1118 .

(43) Asbury, J. B.; Steinel, T.; Fayer, M. D. J. Phys. Chem. B 2004, 108,6544

(44) Wu, H.; Zhang, W. K.; Gan, W.; Cui, Z. F.; Wang, H. F. J. Chem. Phys. 2006, 125, 133203 .

(45) Guo, J.-H.; Luo, Y.; Augustsson, A.; Kashtanov, S.; Rubensson, J.-E.; Shuh, D. K.; Ågren, H.; Nordgren, J. Phys. Rev. Lett. 2003, 91 157401.

(46) Goates, S. R.; Schofield, D. A.; Bain, C. D. Langmuir 1999, 15, 1400. 